\title{
Finite element analysis of steep excavation slope failure by CFS theory*
}

\author{
Huihong Cheng ${ }^{1,2}$ Huai Zhang ${ }^{1,2}$ Bojing Zhu ${ }^{1,2}$ and Yaolin Shi ${ }^{1,2, \uparrow}$ \\ ${ }^{1}$ Key Laboratory of Computational Geodynamics, Chinese Academy of Sciences, Beijing 100049, China \\ ${ }^{2}$ College of Earth Sciences, Graduate University of Chinese Academy of Sciences, Beijing 100049, China
}

\begin{abstract}
The distribution of Coulomb failure stress (CFS) change in the steep excavation slope is calculated by finite element method in this paper, and the failure mechanics under different conditions have been investigated. Comparing the CFSs before and after the slope excavation (stress loading and unloading processes), the dangerous internal zone and the most likely failure external area are attained. Given the shear cracks on the top surface while tensile stress or cracks along the toe of the slope, we analyze the high cutting-angle steep slope in Kaixian county of the Three Gorges Reservoir region. We bring forward that the peak value of CFS after excavation can reach to the order of $0.1 \mathrm{MPa}$, which is greatly higher than that of before. Our preliminary results are useful for optimizing the reinforcement structure during the steep slope stabilization engineering.
\end{abstract}

Key words: Coulomb failure stress; stabilization and failure evaluation; steep slope excavation CLC number: P315.1 Document code: A

\section{Introduction}

With rapid development of economy, more and more engineering activities are being carried out especially in the hilly regions. Slope excavation is one of these behaviors, stability of which is one of the major concerns of design and construction. Especially in Three Gorges region, there are thousands of steep excavation slopes (Luo and $\mathrm{Wu}, 2004$ ). The stabilization evaluation of steep excavation slope is immensely complex in geotechnical engineering. After excavation, the mechanic balance and the stress state of the slope will self-adjust in a certain range, which may produce graveness influence on engineering safety.

In recent years, both qualitative and quantitative methods have been put forward to assess the stability of the excavation slope. For example, limit equilibrium method (LEM), which includes Bishop's method, Janbu's simplified method, and improved sophisticated method, bases on the shear strength along the failure

\footnotetext{
* Received 2 December 2011; accepted in revised form 16 March 2012; published 10 April 2012.

* Corresponding author. e-mail: chenghuihong@163.com

(c) The Seismological Society of China, Institute of Geophysics, China Earthquake Administration, and Springer-Verlag Berlin Heidelberg 2012
}

surface to obtain the minimum safety factor (Griffiths and Lane, 1999; Singh et al., 2008; Pastor and Loute, 2010; Zhang and Zheng, 2004; Zheng et al., 2004; Li et al., 2009; Li and Zhang, 2009). Fuzzy analytical method, neural network method and hierarchical cluster analysis method are widely adopted to estimate the slope stability (Zhang, 1997; Luo and Wu, 2004; Su et al., 2005). Finite difference method (FDM), boundary element method (BEM) and strength reduction method (SRM) are developed to calculate the realistic stress distribution during slope excavation. Recently, the finite element method (FEM) becomes one of the most popular simulation tools to solve this kind of problem (Xu et al., 2003; Song et al., 2005; Zhu et al., 2009b; Zheng et al., 2009; Liang and Ma, 2010).

Once the initial stress, the stress change and the rock stress strength of slope are known, we can evaluate when and where the slope will failure during the excavation process. It is very difficult to obtain the initial stress distribution of the slope due to the lack of high resolution observation stress data in respective slope. However, the relative stress changes before and after the slope excavation is easier to be obtained by the numerical calculation. Based on the previous work (Zhu et al., 2009a, 2011), we take the Coulomb failure stress (CFS) 
theory to evaluate the steep slope excavation (Zhang et al., 2009). The most dangerous internal area, the most possible failure external surface area and the slip angle can be attained through this method. We apply this theory to the high cutting-angle steep slope in Kaixian county of the Three Gorges Reservoir region so as to explore the failure mechanism of the steep excavation slope under a variety of initial stress conditions using finite element method. The CFS change pattern is helpful to evaluate the stability of steep excavation.

\section{Coulomb failure stress (CFS) theory}

\subsection{Introduction}

Recently, the Coulomb failure stress (CFS) theory is used frequently to the study on earthquake triggering. Many researchers have studied the relationship between aftershocks and major shock using CFS theory so as to discuss the earthquake triggering (Stein and Lisowski, 1983; Stein et al., 1992; King et al., 1994; Freed and Lin, 2001; Shi, 2001). Shi and Cao (2010) improved the dynamic CFS formula and calculated the CFS increment of Wenchuan earthquake using three different models. Wan et al. (2007) proposed that the vast majority of aftershocks occurred in the region where the $\Delta \mathrm{CFS}>0$ during their study on Tangshan earthquake. Lei et al. (2008), Lei (2010) and Ge et al. (2009) discussed the impoundment and drainage processes of Zipingpu reservoir and their impact on the Coulomb stress migration in Longmenshan fault zone to investigate the possibilities of triggering the Wenchuan earthquake.

The focal mechanism of an earthquake describes the coseismic deformation in the source region. It is derived from the moment tensor solution of the earthquake, which itself is estimated by analyzing the observed seismic waveforms right after the earthquake. By adopting the constrains from the field observation and aftershock distribution, the rupture direction along the fault plane, the specific fault dip angle, strike angle and the slip angle are achieved, respectively. According to the theory of Mohr-Coulomb and Hook-Brown strength criteria, the shear stress can be expressed as

$$
\tau=c+\mu\left(\sigma_{\mathrm{n}}-p\right),
$$

where $\tau$ is the shear stress of the fault plane, $c$ is the cohesion, $\mu$ is the friction coefficient and $\sigma_{\mathrm{n}}$ is the normal stress of the fault plane (in this paper, the tensile stress is defined as positive), $p$ is the pore pressure, respectively.
Because of the visco-elastic properties of Earth's crust, the stress migration will happen after an earthquake. The local stress state varies dramatically due to the highly focused deformation and strain, especially in the regions close to the epicenter. Ideally, the overall stress state is available through either kinematical or dynamical models. However, if the initial stress is unknown, only the stress change may be calculated according to the Coulomb failure criterion, in which $\triangle \mathrm{CFS}$ is formulated as

$$
\Delta \mathrm{CFS}=\Delta \tau+\mu\left(\Delta \sigma_{\mathrm{n}}+\Delta p\right)
$$

where $\Delta \tau$ and $\Delta \sigma_{\mathrm{n}}$ are the shear stress and normal stress variations along the fault plane, and $\Delta p$ denotes the change in pore pressure, respectively. Coulomb's friction hypothesis is used to determine the combination of shear and normal stresses that will introduce a fracture of the material when $\triangle \mathrm{CFS}$ is positive (Hariri and Bilek, 2011; Katsumata, 2011; He et al., 2011; Ogata, 2010; Santoyoa et al., 2010; Soltanzadeh and Hawkes, 2008; Heidbach and Ben-Avraham, 2007; Robinson, 2003).

In this paper, we put forward the $\triangle \mathrm{CFS}$ criterion to assess the stability of the excavation slope without considering the pore pressure. Given that every particle of slope is surrounded by pseudo fault planes on all sides, we can attain an optimally oriented plane that is most likely instable by rotating the strike angle and slip angle from $0^{\circ}$ to $360^{\circ}$, and the dip angle from $0^{\circ}$ to $90^{\circ}$, as shown in Figure 1. To 2-D problem, we just rotate the strike and dip angles.

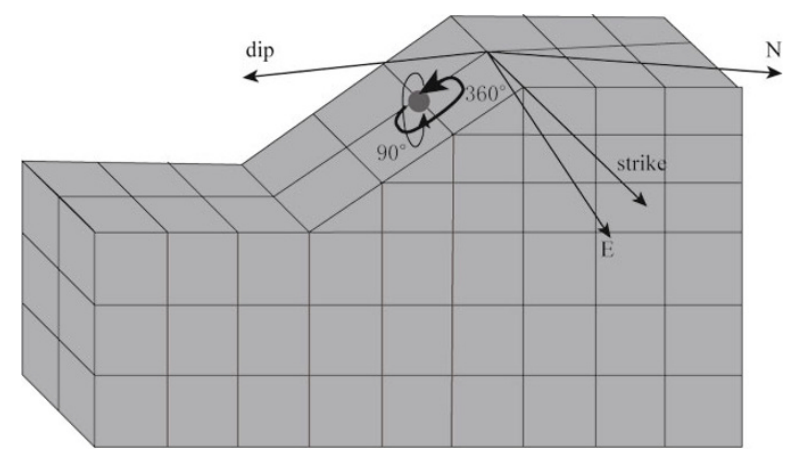

Figure 1 Sketch of attaining the optimal direction of CFS.

Assumed that the initial stress is $\sigma_{i j}^{0}$ and the three characteristic angles of the pseudo fault plane are strike angle $\varphi$, dip angle $\delta$ and slip angle $\lambda$, respectively, the normal vector of the pseudo plane can be expressed as 


$$
\boldsymbol{n}=\left(n_{1}, n_{2}, n_{3}\right)=\left\{\begin{array}{c}
\sin \delta \cdot \cos \varphi \\
-\sin \delta \cdot \sin \varphi \\
\cos \delta
\end{array}\right\} .
$$

The normal stress $\sigma_{\mathrm{n}}^{0}$ and shear stress $\tau_{0}$ of the pseudo fault plane are obtained by

$$
\sigma_{\mathrm{n}}^{0}=\sigma_{i j}^{0} n_{j} n_{i}
$$

and

$$
\tau^{0}=\sigma_{i j}^{0} n_{j} s_{i},
$$

where $s_{i}$ is the slip direction which can be expressed as

$$
s=\left[\begin{array}{c}
\sin \varphi \cos \lambda-\cos \varphi \cos \delta \sin \lambda \\
\cos \varphi \cos \lambda+\sin \varphi \cos \delta \sin \lambda \\
\sin \delta \sin \lambda
\end{array}\right]
$$

After the excavation, the stress field of the slope is rebuilt. If the stress tensor change is $\Delta \sigma_{i j}$, the new stress field can be written as

$$
\sigma_{i j}^{\prime}=\sigma_{i j}^{0}+\Delta \sigma_{i j}
$$

The new normal stress and shear stress are denoted by $\sigma_{\mathrm{n}}^{\prime}$ and $\tau^{\prime}$, respectively. According to equation (2), the CFS and the orientation of the maximum $\triangle$ CFS can be calculated on each pseudo fault plane, which are prone to approximate the direction of the rupture. The envelope of these maximum $\Delta$ CFS directions on each pseudo planes forms the potential failure surface.

\subsection{Model validation}

In order to verify the reliability of this method, we use a simple example to compare it with the result from traditional Morgenstern-Price method, which is a general method of slices developed on the basis of limit equilibrium and requires satisfying equilibrium of forces and moments acting on individual blocks, based on Geo-SLOPE/W accepted as an integrated tool about geotechnical modeling. A homogeneous rock slope with a height of $10 \mathrm{~m}$ and length of $20 \mathrm{~m}$ is considered, as shown in Figure 2. The cohesive strength of the rock is $5 \mathrm{kPa}$ and the friction angle is $20^{\circ}$. The unit weight, elastic modulus and Poisson ratio of the rock slope are $15 \mathrm{kN} / \mathrm{m}^{3}, 1.0 \mathrm{GPa}$ and 0.3 , respectively.

We calculated the minimum safety factor and the most likely sliding surface after excavation using Morgenstern-Price method (Figure 3a). In general, the minimum safety factor is an indicator of estimating the stability of slope based on the Coulomb failure criterion. Its value is equal to the ratio of sliding force to skid resistance. Figure $3 \mathrm{~b}$ shows the result from our finite element method based on the linear elastic theory and $\triangle \mathrm{CFS}$ calculation. By introducing the FEM method, we can detect not only the most dangerous part but also the possible crack direction and the crack properties on each point of the slope, whether they are tensile crack or shear crack according to the normal stress and shear stress changes. If the normal stress variation is positive and larger than shear stress change, the crack is defined as dilatation crack. Otherwise, the crack is shear crack. At the same time, combining the $\triangle \mathrm{CFS}$ contours, we joint the optimally oriented plane of every point to attain the slip plane. As shown in Figures 3a and $3 \mathrm{~b}$, those results from different methods agree with each other very well.

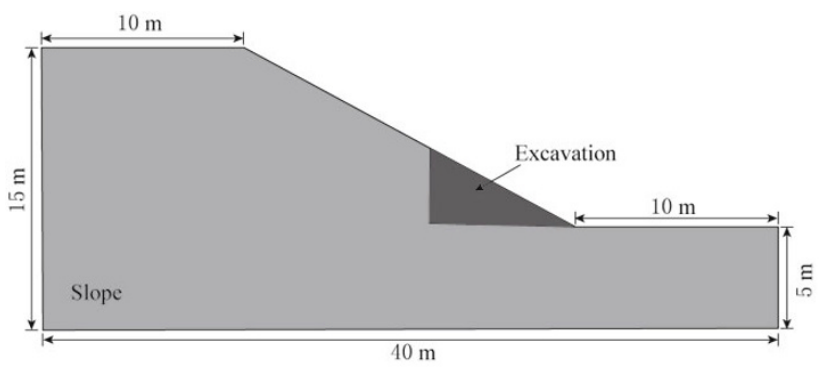

Figure 2 The sketch of the benchmark model.

Figure 3a shows the safe factor and failure surface using Morgenstern-Price method. The red quiver is the feature of the GEO/SLOPE soft to show the entry and exit location of the slip surface, which means that the most possible start parts of the slope crest and the end parts of the slope foot. Figure $3 \mathrm{~b}$ shows the envelope of the CFS changes and the crack type (every 100 points). The black pseudo fault plane shows the contour of the $\Delta \mathrm{CFS}$ and the most possible slip surface.

\section{Application of $\triangle$ CFS method to the high cutting slope stability analysis}

In this paper, we analyze the high cutting rock slope located in the north of Kaixian in Three Gorges region, as shown in Figure 4. After excavation, the slope deformation and rock collapse appeared, which are the serious threat to lives and property of the local people. A reasonable stress analyses are needed to be proposed on the possible engineering solutions before the appropriate measures of reinforcement are taken. 

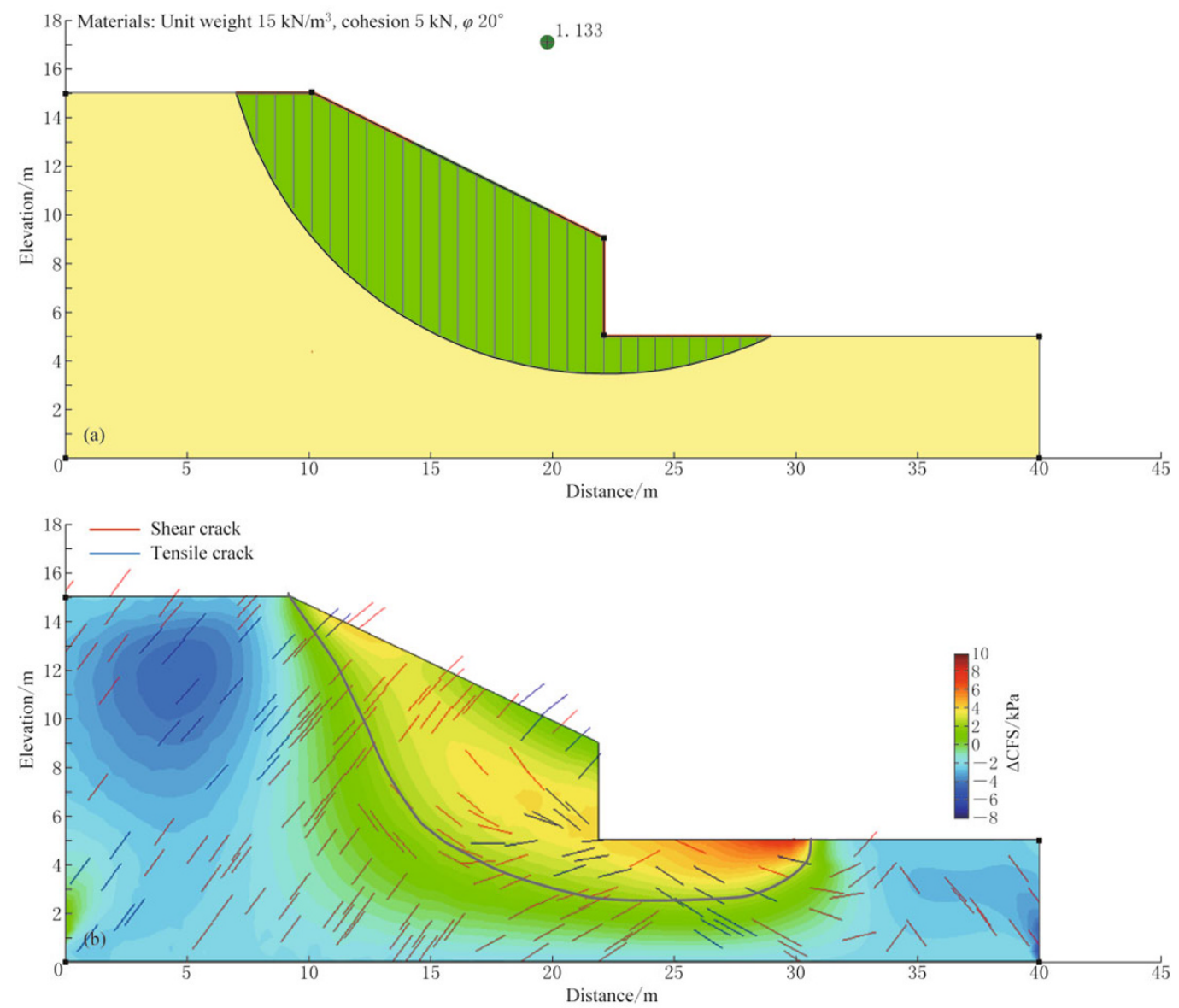

Figure 3 Comparison between Morgenstern-Price method (a) and $\triangle$ CFS method in this study (b).

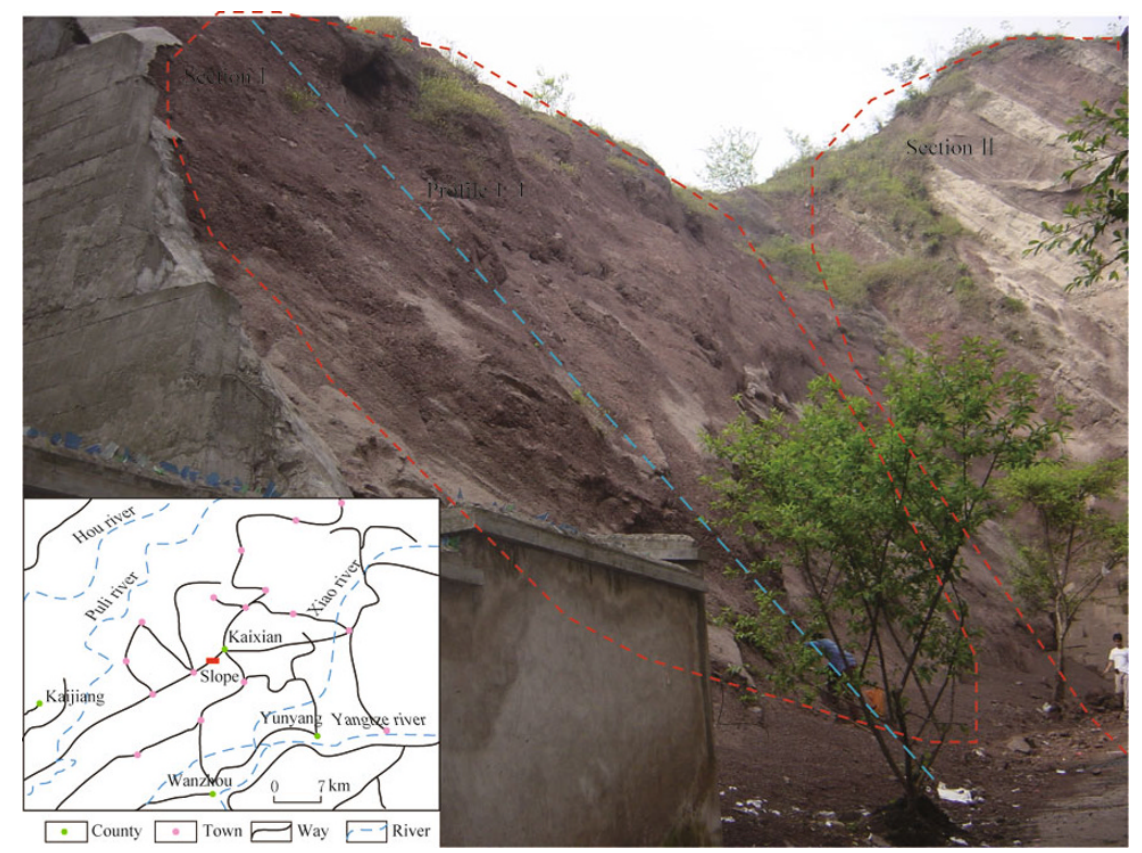

Figure 4 Geological survey of the excavated slope. The slope is composed of consequent part (section I) and tangential part (section II). It is one of the forty nine protective slopes in the city, and it is only less than $4 \mathrm{~m}$ away from the civilian buildings. The maximum height of the slope is $37.1 \mathrm{~m}$ and the length is $80 \mathrm{~m}$. 
The slope inclination varies from $57^{\circ}$ to $333^{\circ}$ and its dip angle varies from $53^{\circ}$ to $57^{\circ}$. The total area is $3520 \mathrm{~m}^{2}$. Based on the geological field observation data, we constructed the numerical simulation model according to the section profile 1-1, as shown in Figure 5. We found that the rock slope is composed of the moderately weathered mudstone $\left(\mathrm{J}_{2} \mathrm{~s}\right)$. The slope summit is composed of Quaternary sediment $\left(\mathrm{Q}_{4}^{\mathrm{el}+\mathrm{dl}}\right)$, gravel stone and intense weathering mudstone $\left(\mathrm{Q}^{\mathrm{s}}\right)$.

The geological profile 1-1 shows clearly that the Quaternary sediment $\left(\mathrm{Q}_{4}^{\mathrm{el}+\mathrm{dl}}\right)$ and intense weathering mudstone $\left(\mathrm{Q}^{\mathrm{s}}\right)$ are comparatively thin. Their thicknesses is only $0.2-3.0 \mathrm{~m}$, while the thickness of moderately weathered mudstone $\left(\mathrm{J}_{2} \mathrm{~s}\right)$ is around $1288 \mathrm{~m}$.

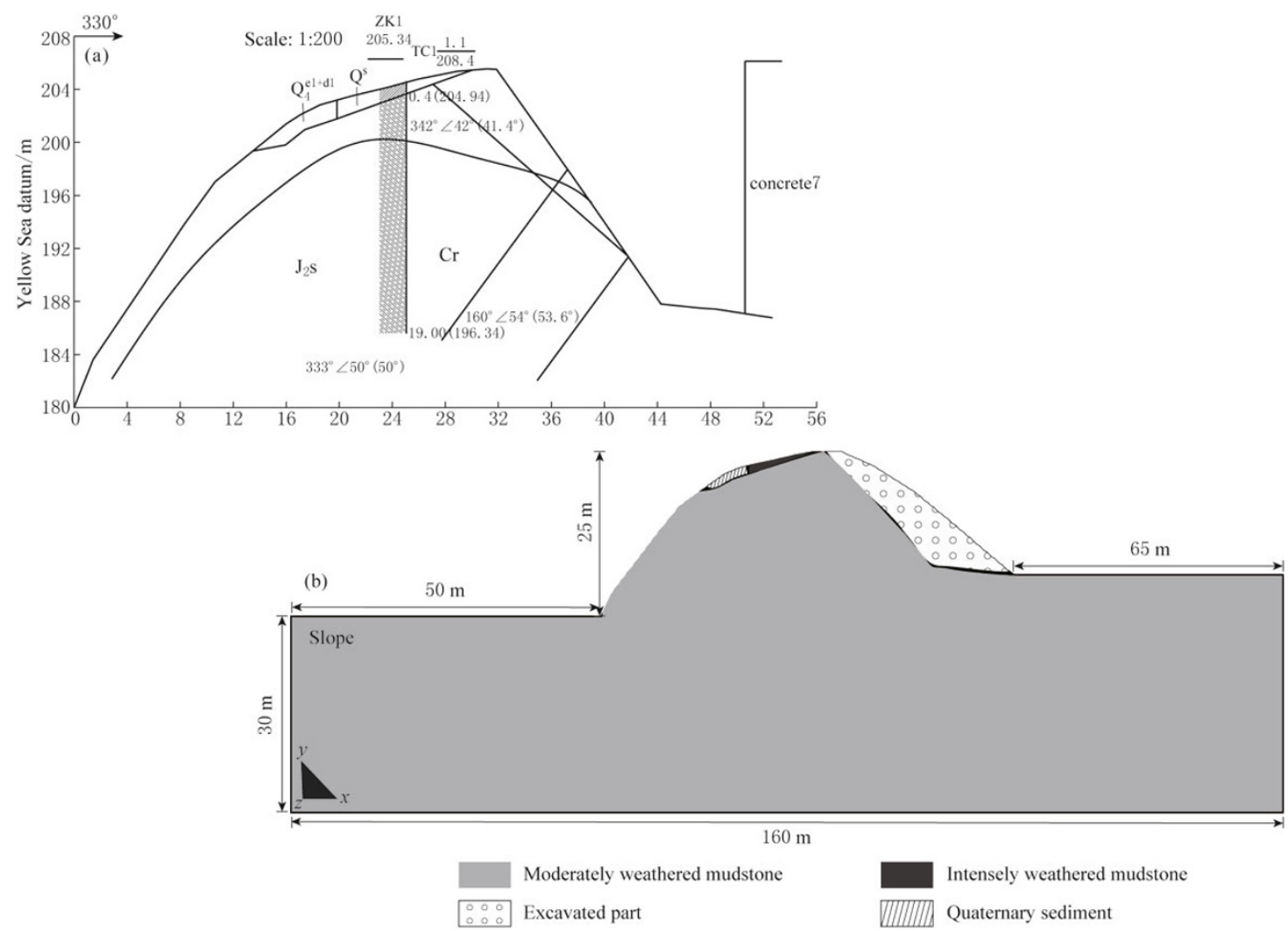

Figure 5 Geological profile 1-1 (upper-left) and the 2D physical model of the investigated slope.

\subsection{Numerical model}

The rock mass in the Kaixian region is regarded as elastical media. Based on linear elastical theory, the continuity equations for model can be expressed by the following:

$$
\nabla \cdot \boldsymbol{u}=0
$$

the geometric equation is

$$
\dot{\varepsilon}_{i j}=\frac{1}{2}\left(u_{i, j}+u_{j, i}\right),
$$

the equilibrium equation (where the body forces are neglected) is

$$
\frac{\partial \sigma_{i j}}{\partial x_{j}}+f_{i}=0
$$

and the constitutive equation is

$$
\left\{\begin{array}{l}
\sigma_{x x} \\
\sigma_{y y} \\
\sigma_{z z} \\
\sigma_{y z} \\
\sigma_{x z} \\
\sigma_{x y}
\end{array}\right\}=\frac{E}{(1+\nu)(1-2 \nu)}\left\{\begin{array}{cccccc}
1-\nu & \nu & \nu & & \\
\nu & 1-\nu & \nu & & \\
\nu & \nu & 1-\nu & & \\
& & & 0.5-\nu & \\
& & & & 0.5-\nu & \\
& & & & 0.5-\nu
\end{array}\right\}\left\{\begin{array}{l}
\varepsilon_{x x} \\
\varepsilon_{y y} \\
\varepsilon_{z z} \\
\varepsilon_{y z} \\
\varepsilon_{x z} \\
\varepsilon_{x y}
\end{array}\right\},
$$


where $E$ is the Young's modulus and $\nu$ is Poisson's ratio. In order to improve the accuracy of our numerical model, the whole computing domain is enlarged to a great extend to reduce the numerical errors from boundary conditions. In our numerical model, the horizontal size dimension is around 2.5 times as large as that of the slope height. Vertically, the computing domain's highness is twice as high as that of the actual slope height. In total, there are 14600 triangle elements consisting of 7530 nodes. Because the initial stresses are unknown, we compared the results from four different kinds of models with different kinds of boundary con- ditions. Those physical models and their correspondent parameters are shown in Tables 1 and 2. About the value of the friction coefficient $\mu$, we define $\mu=\tan \phi$, where $\phi$ is the friction angle.

Table 1 Model boundary conditions

\begin{tabular}{cccc}
\hline Boundary & Model I & Model II & Model III \\
\hline Surface boundary & Freedom & Freedom & Freedom \\
Left boundary & Fixed & $0.5 \rho$ gh & $\rho$ gh \\
Lateral and & Fixed & Fixed & Fixed \\
bottom boundary & & & \\
\hline
\end{tabular}

Table 2 Physical parameters of the slope

\begin{tabular}{ccccc}
\hline Rock type & Weight $/\left(\mathrm{kN} \cdot \mathrm{m}^{3}\right)$ & Young's modulus $/ \mathrm{MPa}$ & Poisson's ratio & Cohesion/MPa \\
\hline Quaternary sediment & 19.5 & 18.5 & 0.25 & 0.015 \\
Intensely weathered mudstone & 24.80 & 6000 & 0.22 & 0.20 \\
Moderately weathered mudstone & 25.38 & 7000 & 0.20 & 0.64 \\
\hline
\end{tabular}

\subsection{Simulation and discussion}

\subsubsection{Stress increments of each model}

Figure 6 shows the variation of stress $\left(\sigma_{x x}, \sigma_{x y}\right.$ and $\left.\sigma_{y y}\right)$ for each model. After excavation, the stresses are adjusted, especially the one at the foot of the slope. Comparing three models with different boundary conditions, on the whole, the distributions of $\sigma_{x x}, \sigma_{x y}$ and $\sigma_{y y}$ are nearly the same, but we can see that there are still many differences in the distributions of $\sigma_{x x}$ and $\sigma_{x y}$. Because of the existing crust tectonics in the left boundary of model $I$, there emerge $\sigma_{x x}$ centered largely in the left part of the slope and more obvious $\sigma_{x y}$ concentration in the right toe of the slope, which indicates that the crust tectonic stress field should not be neglected, especially in dealing with the tension crack near the toe of the slope.

\subsubsection{Displacement increments of model I}

Figure 7 shows each component of the displacement increment vector in model I. Here, we take model I for an example to analyze the characteristics of the excavated slope. Compared with the displacement increments in $x$ and $y$ directions, the vertical displacement increments is one order of magnitude larger than horizontal ones. And the largest normal stress increments are nearly twice as many as the horizontal normal stress at the foot of the excavated slope, where appears the stress concentration. There are positive shear stress increments near the slope surface while negative shear stress increments are at the foot of slope.

\subsection{3 $\triangle$ CFS of model I}

Substituting the variable stress parameters into equations (3) and (4), we attain the distribution of the $\triangle \mathrm{CFS}$ in each model with the maximum value of each model being $1.95 \times 10^{5} \mathrm{~Pa}, 2.95 \times 10^{5} \mathrm{~Pa}$ and $2.2 \times 10^{5} \mathrm{~Pa}$ respectively. Taking the model I for an example, the optimal fracture direction is shown in Figure 8. We know that the largest CFS increments appear at the foot of the slope which are the most dangerous parts. For the more upper load reduction, the more vertical normal stress reduced. From equation (2), the CFS of the excavated slope is larger than that before excavation. There are shear cracks on the top excavation surface while there are tensile cracks at the toe of the slope. This can interpret the phenomenon why there are a lot of rubble and broken stones in the field. So we should adopt the reinforcement measures at the foot of the slope when we excavate slope and reinforce the excavated face. Comparison of the four models shows that the maximum $\triangle \mathrm{CFS}$ appears in model II, which demonstrates the bigger the tectonic stress, the more unstable the excavation slope.

\section{Conclusions}

Now, we can not attain exactly the unstable parts of the excavation slope when we do not know the tectonic stress. According the CFS theory, we can know the relatively more dangerous parts where the $\triangle \mathrm{CFS}$ is larger than zero. Based on CFS theory, the steep excavation slope is analyzed. From the variable simulation of CFS field before and after the excavation, the most dangerous internal area and the most likely failure 

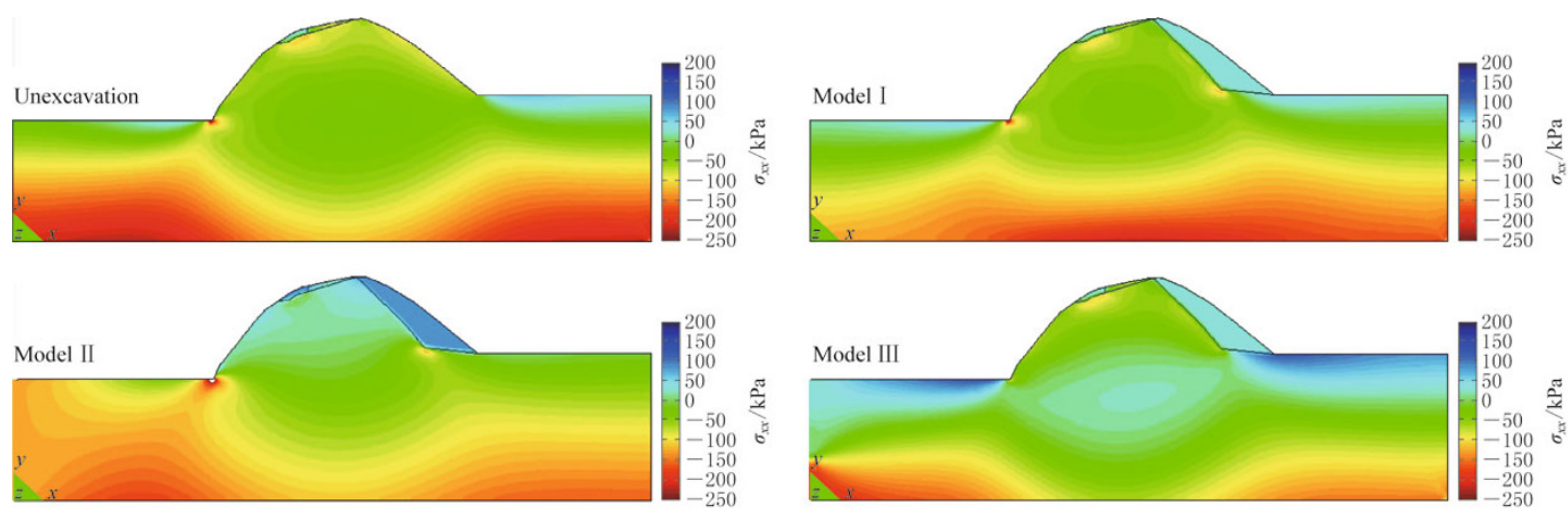

(a)
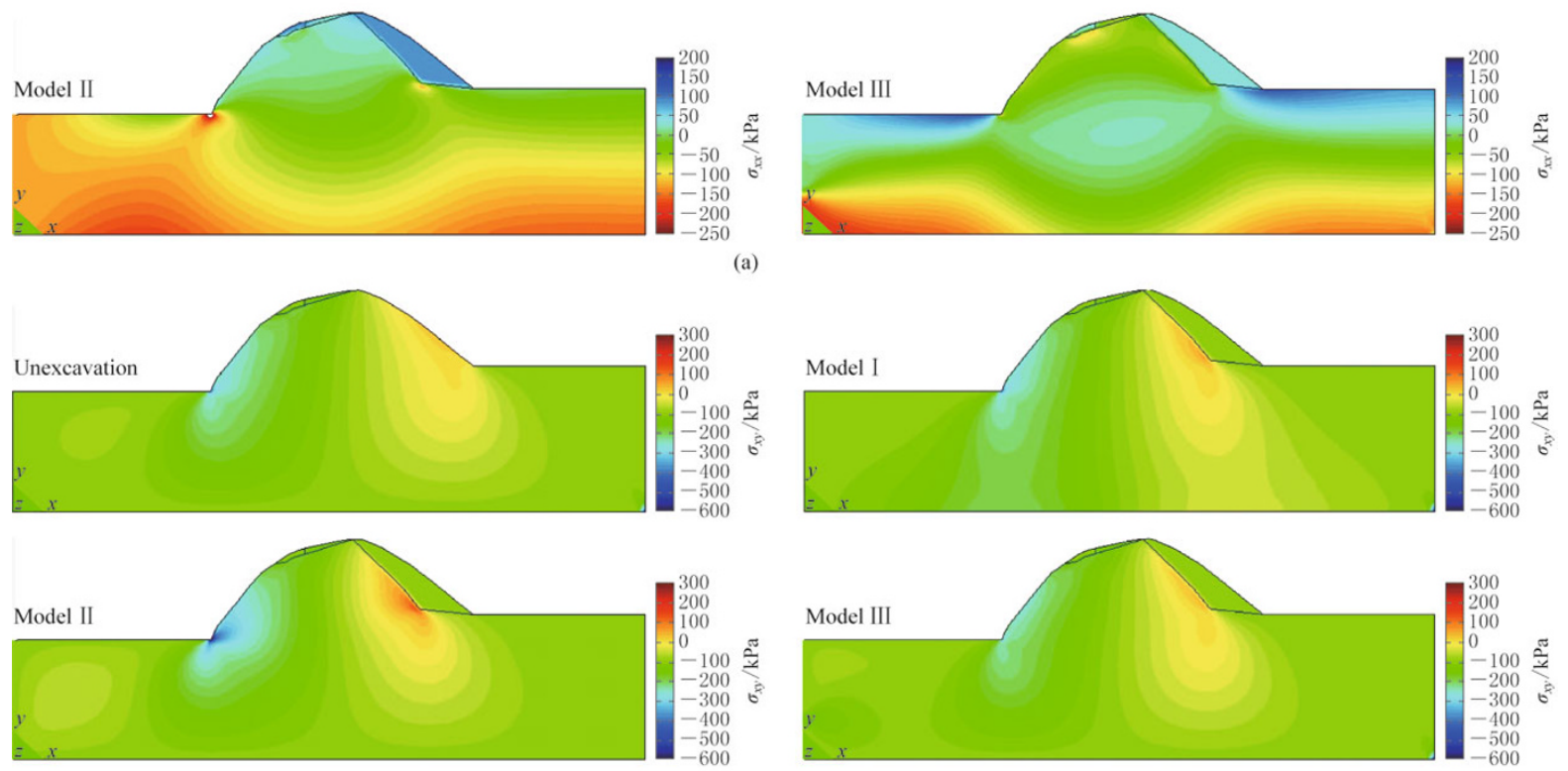

(b)
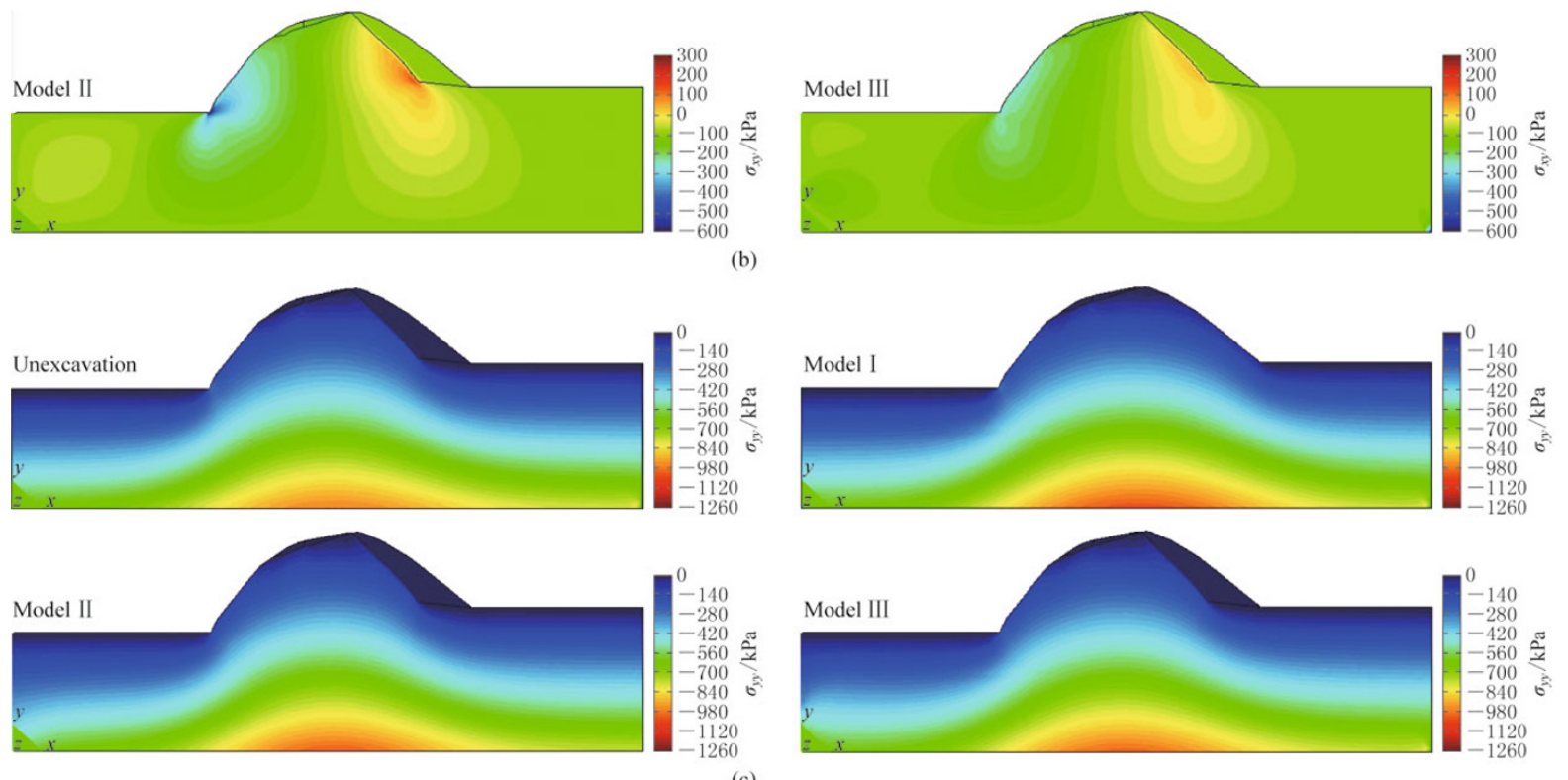

(c)

Figure 6 The results of stress changes of each model. (a) Stress $\sigma_{x x}$; (b) Stress $\sigma_{x y}$; (c) Stress $\sigma_{y y}$.

external surface area are attained. Through analyzing the high cutting-slope at the Kaixian county in the Three Gorges Reservoir region, we obtain that the CFS after excavation is bigger than that before excavation; there are shear cracks on the top excavation surface while the tensile cracks along the toe of the slope and the largest CFS increment reaches to the order of 0.1 $\mathrm{MPa}$. King et al. (1994) indicated that obvious seismic activity could be observed if the stress change reaches $0.01 \mathrm{MPa}$. So, even the $\triangle \mathrm{CFS}$ is only several $\mathrm{kPa}$, the rock may be destroyed and the slope may collapse. At the same time, the results show that the tectonic stress boundary conditions have a great influence on the val- ue of $\Delta$ CFS. The difference of the maximum $\Delta$ CFS can reach to $30 \%$ in the three models. The CFS distribution as position function can be helpful to study the failure mechanism of steep excavation slope, which is favorable for designing and taking reinforcement measurement in engineering application.

In this paper, we just put forward the effects of the stress boundary. According to mechanical mechanism, we will make further study on the differences between Dirichlet displacement boundary and Newman stress boundary in the problems about excavation slope. And we also will consider the factor of rainfall and the softening effect of the rock or fault into our models. 

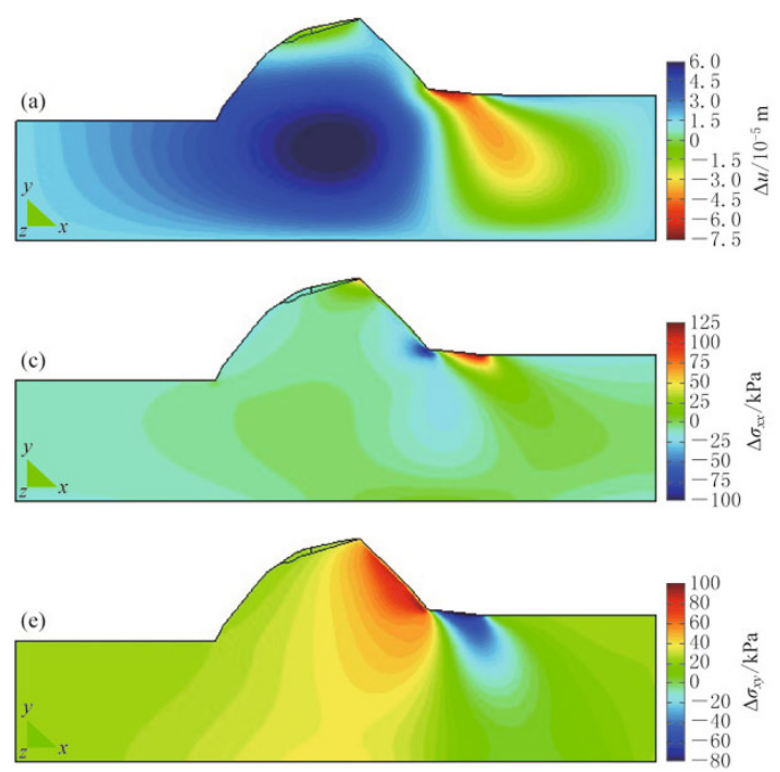
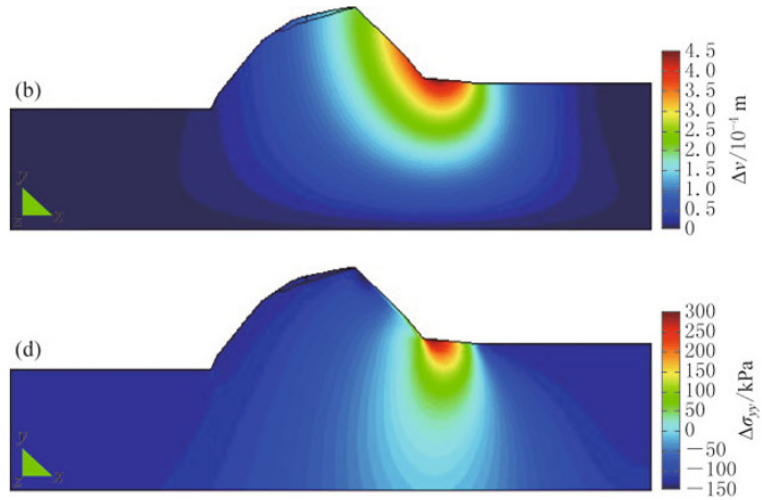

Figure 7 Increments of several vectors in model I. (a) Horizontal displacement increment $\Delta u$; (b) Vertical displacement increment $\Delta v$; (c) Stress increment $\Delta \sigma_{x x}$ in $x$ direction; (d) Stress increment $\Delta \sigma_{y y}$ in $y$ direction; (e) Shear stress increment $\Delta \sigma_{x y}$.

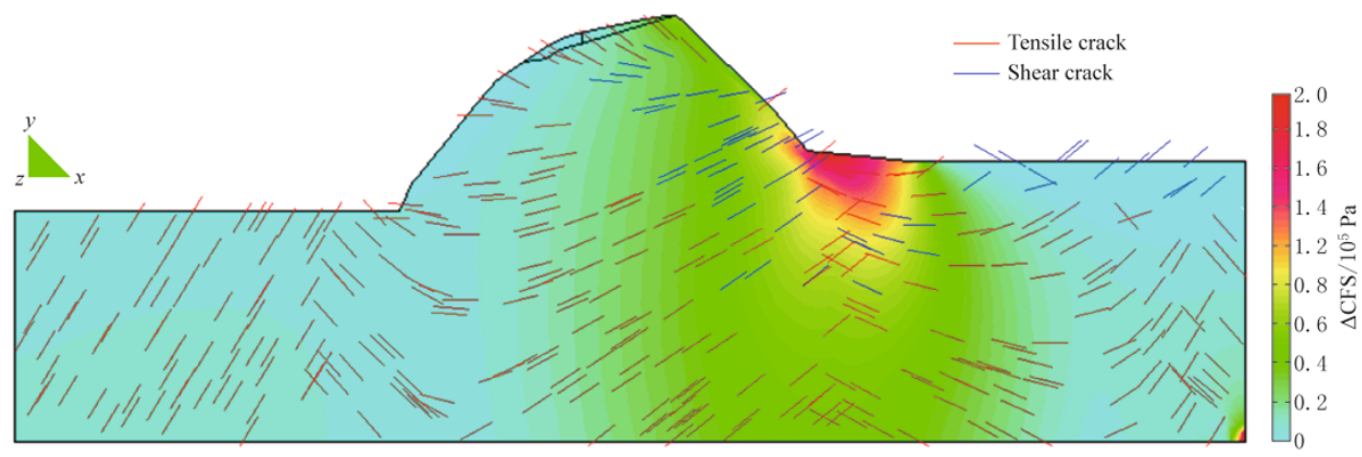

Figure 8 Distribution of the $\triangle \mathrm{CFS}$ of model I.

Acknowledgements The study was supported by Sinoprob-Deep Exploration Program in China sponsored by Ministry of Land and Resources of the People's Republic of China (No. 0819011A90) and National Natural Science Foundation of China (No. D0408/4097409).

\section{References}

Freed A M and Lin J (2001). Delayed triggering of the 1999 Hector Mine earthquake by viscoelastic stress transfer. Nature 411: 180-183.

Ge S M, Liu M, Lu N, Godt J W and Luo G (2009). Did the Zipingpu Reservoir trigger the 2008 Wenchuan earthquake? Geophys Res Lett 36: 1-5.

Griffiths D V and Lane P A (1999). Slope stability analysis by finite elements. Geotechnique 49(3): 387-403.

Hariri M E and Bilek S L (2011). Stress changes and aftershock distribution of the 1994 and 2006 Java subduction zone earthquake sequences. J Geophys Res 116: B06306.

He T, Li S Y, Zhang H K, Zhao T L and Qian F Y (2011). Coulomb failure stress change in slip weakening model and remote triggering of earthquakes. Acta Seismologica Sinica 32(2): 165-186 (in Chinese with English abstract).

Heidbach O and Ben-Avraham Z (2007). Stress evolution and seismic hazard of the Dead Sea Fault System. Earth Planet Sci Lett 257: 299-312.

Katsumata K (2011). Precursory seismic quiescence before the $M_{\mathrm{W}}=8.3$ Tokachi-oki, Japan, earthquake on 26 September 2003 revealed by a re-examined earthquake catalog. J Geophys Res 116: B10307.

King G C P, Stein R S and Lin J (1994). Static stress changes and the triggering of earthquake. Bull Seismol Soc Am 84(3): 935-953

Lei X L (2010). Possible roles of the Zipingpu Reservoir in triggering the 2008 Wenchuan earthquake. J Asian Earth 
Sci 40(4): 844-854.

Lei X L, Ma S L and Wen X Z (2008). Integrated analysis of stress and regional seismicity by surface loading - A case study of Zipingpu reservoir. Seismology and Geology 30(4): 1 046-1 064 (in Chinese with English abstract).

Li A J, Merifield R S and Lyamin A V (2009). Limit analysis solutions for three dimensional undrained slopes. Computers and Geotechnics 36(8): 1 330-1 351.

Li L M and Zhang G X (2009). Method for analyzing the slope stability based on potential slip line theory. In: Proceedings of the 2009 Second International Conference on Intelligent Computation Technology and Automation. IEEE Computer Society, Washington DC, 550-553.

Liang R Y and Ma Y M (2010). Three-dimensional finite element study of arching behavior in slope/drilled shafts system. International Journal for Numerical and Analytical Methods in Geomechanics 34(11): 1 157-1 168.

Luo Y H and Wu F Q (2004). The basic characteristics and control measures of high cutting-slope at the Three Gorges Reservoir. The Chinese Journal of Geological Hazard and Control 15(S1): 115-118 (in Chinese).

Ogata Y (2010). Anomalies of seismic activity and transient crustal deformations preceding the 2005 M7.0 earthquake west of Fukuoka. Pure Appl Geophys 167(8-9): $1115-1127$

Pastor F and Loute E (2010). Limit analysis decomposition and finite element mixed method. J Computat Appl Math 234(7): 2 213-2 221.

Robinson R (2003). Fault interactions and subduction tectonics: a re-examination of the Weber, New Zealand, earthquake sequence of 1990. Geophys J Int 154(3): 745753 .

Santoyoa M A, García-Jerez A and Luzón N (2010). A subsurface stress analysis and its possible relation with seismicity near the Itoiz Reservoir, Navarra, Northern Spain. Tectonophysics 482(1-4): 205-215.

Shi Y L (2001). Stress triggers and stress shadows: how to apply these concepts to earthquake prediction. Earthquake 21(3): 1-7 (in Chinese with English abstract).

Shi Y L and Cao J L (2010). Some aspects in static stress change calculation - case study on Wenchuan earthquake. Chinese J Geophys 53(1): 102-110 (in Chinese with English abstract).

Singh T N, Gulati A and Dontha L (2008). Evaluating cut slope failure by numerical analysis - a case study. Nat Hazards 47: 263-279.

Soltanzadeh H and Hawkes C D (2008). Semi-analytical models for stress change and fault reactivation induced by reservoir production and injection. Journal of Petroleum Science and Engineering 60: 71-85.

Song Y K, Zhao Y M and Zheng Y R (2005). An analysis of the slope by FEM in the Three-Gorge Reservoir zone. Journal of Logistical Engineering University 2: 70-73 (in Chinese with English abstract).

Stein R S and Lisowski M (1983). The 1979 Homestead
Valley earthquake sequence, California: control of aftershocks and postseismic deformation. J Geophys Res 88(B8): 6 477-6 490.

Stein R S, King G C P and Lin J (1992). Change in failure stress on the southern San Andreas fault system caused by the 1992 magnitude=7.4 Landers earthquakes. Science 258: 1 328-1 332.

Su H Z, Wu Z R, Dai H C and Wen H P (2005). Multipleindex assessment for global stability of high-steep rock slope of the Three Gorges Project permanent shiplock. Chinese Journal of Rock Mechanics and Engineering Geology 24(1): 23-31 (in Chinese with English abstract).

Wan Y G, Shen Z K, Zeng Y H and Shen S Z (2007). Evolution of cumulative Coulomb failure stress in northeastern Qinghai-Xizang (Tibetan) Plateau and its effect on large earthquake occurrence. Acta Geotechnica Sinica 20(2): 117-132.

Xu J, Liu D S and Zheng Y R (2003). Analysis of elasticplastic stochastic finite element method based on probabilistic yield criterion. Chinese Journal of Rock Mechanics and Engineering 22(3): 395-399 (in Chinese with English abstract).

Zhang H, Wu Z L, Zhang D N, Liu J, Wang H, Yan Z Z and Shi Y L (2009). Virtual ChuanDian - A parallel numerical modeling of Sichuan-Yunnan regional strong earthquake activities: Model construction and parallel simulation. Science in China (Series D) 52(10): 1 585-1 598.

Zhang L Y and Zheng Y R (2004). Effect of moment axis on safety factors by extend simplified Bishop method. Rock and Soil Mechanics 8: 1 239-1 243.

Zhang M (1997). Application of fuzzy analysis in slope stability evaluation. Chinese Journal of Rock Mechanics and Engineering 16(5): 490-495 (in Chinese with English abstract).

Zheng Y R, Shi W M and Yang M C (2004). Discussion on imbalance thrust force method and Sarma's method. Chinese Journal of Rock Mechanics and Engineering 17: 3 030-3 036.

Zheng Y R, Tan X S and Zhao S Y (2009). Application of strength reduction FEM in fording slope. Hydro-Science and Engineering (4): 1-10 (in Chinese with English abstract).

Zhu B J, Liu C, Shi Y L, Sun D S and Zhang K (2011). Application of flow driven pore-network crack model to Zipingpu reservoir and Longmenshan slip. Science China Physics, Mechanics and Astronomy 54(8): 1 532-1 540.

Zhu B J, Shi Y L, Sukop M C, Li Y B and Qin T Y (2009a). Analysis of 3D fluid driven crack propagation problem in co-seismic slip under $\mathrm{P}$ - and S-waves by hybrid hypersingular integral method. Computer Methods in Applied Mechanics and Engineering 198: 2446.

Zhu M, Ma C L and Tang R (2009b). Slope stability analysis of open pit mine based on finite difference method. Second International Conference on Information and Computing Science. 21-22 May 2009, Manchester, 208-211. 